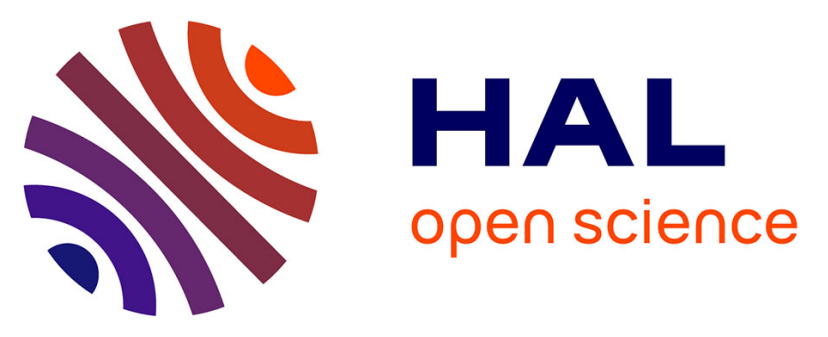

\title{
Estimating the greenhouse gas fluxes of European grasslands with a process-based model: 2. Simulations at the continental level
}

Nicolas Vuichard, Philippe Ciais, Nicolas Viovy, Pierluigi Calanca, Jean-François Soussana

\section{To cite this version:}

Nicolas Vuichard, Philippe Ciais, Nicolas Viovy, Pierluigi Calanca, Jean-François Soussana. Estimating the greenhouse gas fluxes of European grasslands with a process-based model: 2. Simulations at the continental level. Global Biogeochemical Cycles, 2007, 21, pp.GB1005. 10.1029/2005GB002612 . hal-02664391

\section{HAL Id: hal-02664391 \\ https://hal.inrae.fr/hal-02664391}

Submitted on 27 Feb 2022

HAL is a multi-disciplinary open access archive for the deposit and dissemination of scientific research documents, whether they are published or not. The documents may come from teaching and research institutions in France or abroad, or from public or private research centers.
L'archive ouverte pluridisciplinaire HAL, est destinée au dépôt et à la diffusion de documents scientifiques de niveau recherche, publiés ou non, émanant des établissements d'enseignement et de recherche français ou étrangers, des laboratoires publics ou privés. 


\title{
Estimating the greenhouse gas fluxes of European grasslands with a process-based model:
}

\section{Simulations at the continental level}

\author{
Nicolas Vuichard, ${ }^{1,2}$ Philippe Ciais, ${ }^{1}$ Nicolas Viovy, ${ }^{1}$ Pierluigi Calanca, ${ }^{3}$ \\ and Jean-François Soussana ${ }^{4}$
}

Received 2 September 2005; revised 28 July 2006; accepted 30 August 2006; published 19 January 2007.

[1] We apply a simulation model in order to quantify the patterns of carbon and nitrogen cycling within European grasslands. We map the fluxes of $\mathrm{CO}_{2}, \mathrm{~N}_{2} \mathrm{O}$ and $\mathrm{CH}_{4}$ exchanged with the atmosphere as controlled by climate and management conditions. We distinguish between grazing and cutting practice. Because geo-referenced management information for grasslands does not exist at the scale of Europe, we develop a new and robust set of rules defining some management variables. We then perform realistic simulations in term of $\mathrm{N}$ fertilization using a national level data set. The model results at European scale are compared with agricultural statistics (yield, animal stocks), which shows that our very simple management calculation is reasonably realistic. We also compare the simulated seasonal cycle of grassland phenology as calculated by PASIM with remote sensing observations from the EOS-TERRA-MODIS satellite, which shows a good general agreement. Emission factors for soil $\mathrm{N}_{2} \mathrm{O}$ and grazing animals $\mathrm{CH}_{4}$ emissions are diagnosed from the model runs and shown to be comparable to those of previous experimental surveys. We investigate impact of $\mathrm{N}$ fertilization on NPP and C storage potential, $\mathrm{N}_{2} \mathrm{O}$ emissions by soils and $\mathrm{CH}_{4}$ emissions by ruminants. We conclude that, for different time horizon, $\mathrm{CH}_{4}$ and $\mathrm{N}_{2} \mathrm{O}$ sources are lower than the potential sink of $\mathrm{CO}_{2}$, on a carbon equivalent basis. This result is independent of fertilization intensity but assumes that the current soil $\mathrm{C}$ stocks are below the long-term equilibrium values.

Citation: Vuichard, N., P. Ciais, N. Viovy, P. Calanca, and J.-F. Soussana (2007), Estimating the greenhouse gas fluxes of European grasslands with a process-based model: 2. Simulations at the continental level, Global Biogeochem. Cycles, 21, GB1005, doi:10.1029/2005GB002612.

\section{Introduction}

[2] We develop and apply a simulation model to quantify the patterns of carbon and nitrogen cycling within managed European grasslands, and to map the fluxes of $\mathrm{CO}_{2}, \mathrm{CH}_{4}$ and $\mathrm{N}_{2} \mathrm{O}$ exchanged with the atmosphere, being controlled by climate and management conditions [Soussana et al., 2004]. We adopt a process oriented modeling approach of grassland biogeochemistry. One advantage of a process model is that it allows us to quantify explicitly and consistently how climate and soil drivers control the sources and sinks of different gases, their spatial distribution and their temporal variability [Vuichard et al., 2007]. In addi-

\footnotetext{
${ }^{1}$ Laboratoire des Sciences du Climat et de l'Environnement, CEACNRS, Gif-sur-Yvette, France.

${ }^{2}$ Now at Department of Forest Science and Environment, University of Tuscia, Viterbo, Italy.

${ }^{3}$ Agroscope Reckenholz-Tänikon, Research Station ART Air Pollution and Climate Group, Zurich, Switzerland. France.

${ }^{4}$ INRA, UR874 Grassland Ecosystem Research, Clermont-Ferrand,

Copyright 2007 by the American Geophysical Union. 0886-6236/07/2005GB002612
}

tion, such a model is useful to elucidate the interplay of different processes and their interactions, in order, for instance, to formulate better strategies for reducing the emissions or enhancing the sinks of greenhouse gases over grasslands, an important ecosystem covering $20 \%$ of the European continent [Janssens et al., 2003]. Further, we need consistent maps at the scale of the European continent of the distribution uncertainties of $\mathrm{CO}_{2}, \mathrm{CH}_{4}$ and $\mathrm{N}_{2} \mathrm{O}$ fluxes in order to help ill-constrained atmospheric inversions that quantify regional budget from atmospheric concentration signals [Peylin et al., 2005]. In this respect, there is almost no comprehensive model of the greenhouse gas fluxes of grassland ecosystems over Europe at the moment.

[3] We use the PASIM process-based grassland biogeochemical model. The model (version 3.7) calculates the dynamic evolution of $\mathrm{CO}_{2}$ fluxes and carbon pools [Riedo et al., 1998], soil $\mathrm{N}_{2} \mathrm{O}$ emissions from nitrification and denitrification processes [Schmid et al., 2001] and $\mathrm{CH}_{4}$ emissions from grazing livestock [Vuichard et al., 2007]. In this latter companion paper, we ran the PASIM model at five selected sites of the GREENGRASS project (EVK2CT2001-00105) with contrasted management conditions 
(grazing or cutting, low or high level of $\mathrm{N}$ fertilization), and evaluated its output against eddy-covariance NEE, shoot biomass and leaf area index (LAI) measurements.

[4] From that study, we inferred that (1) the modifications that were made to the model improved the fit to the data, (2) better results were obtained for cut grasslands than for grazed ones, and (3) the model was better able to simulate newly sown grasslands than seminatural ones [Vuichard et al., 2007].

[5] Here we apply the same model at the continental level (section 2.1) using gridded climate and soil variables over Europe (section 2.2). We then evaluate the model results with satellite and ground-based data, including statistical information on management. Finally, we investigate the sensitivity of regional grassland carbon and GHG budgets to $\mathrm{N}$-fertilizer additions, by comparing the results from simulations with realistic $\mathrm{N}$-fertilizer applications to an upper and lower bound hypothesis for $\mathrm{N}$ additions.

[6] A process-based modeling approach is well suited to map biogeochemical ecosystem functioning into GHG fluxes, but it certainly falls short of taking into account key socio-economic constraints on grassland management. Because of that, we cannot claim a priori to provide more realistic estimates of grasslands greenhouse emissions than those based on more empirical methods [Freibauer, 2003]. Rather, we use the model in order to identify and separate the relative importance of each process, and to analyze the interactions between different processes. We investigated the impact of cutting vs. animal grazing practice on the GHG source and sink function of grasslands, and tested whether European grasslands $\mathrm{CO}_{2}$ sinks offset the sources of non- $\mathrm{CO}_{2}$ gases $\left(\mathrm{CH}_{4}\right.$ and $\left.\mathrm{N}_{2} \mathrm{O}\right)$ in terms of greenhouse warming potential.

\section{Methods}

\subsection{Model and Upscaling Scheme Descriptions}

[7] The PASIM grassland model developed by Riedo et al. [1998] is derived from the Hurley Pasture Model [Thornley, 1998]. Later, Schmid et al. [2001] improved the simulation of the nitrogen cycle by introducing ammonia, and Vuichard et al. [2007] improved the calculation of aboveground vegetation dynamics to obtain a realistic LAI decrease at the end of the growing season. In the upscaling exercise at the continental level, the PASIM model by itself does not require any changes in its biogeochemical structure. It is mechanistic, relatively generic, and can be driven by commonly available input climate and soil fields. All plant parameter values have been set to constants, thereby assuming constant properties of the grassland vegetation, and the same parameter values as in the work of Vuichard [2005] have been used.

[8] We chose to integrate PASIM on a regular grid at a spatial resolution of $1^{\circ}$ by $1^{\circ}$. Such a relatively coarse resolution, comparable to the one of current Global Dynamic Vegetation Models, was determined by computing power limitations. It is sufficient to represent regional meteorological regimes in plain regions. The model resolution is however too coarse for capturing local soil heterogeneities and their impact on GHG fluxes from grasslands.

\subsection{Input Data}

[9] If climate and soil fields are commonly available in a gridded form, there is virtually no geo-referenced data on grassland management at the European level. PASIM requires as an input, for any grid point, whether grasslands are grazed or cut, and for each option, respectively the animal stocking rate and grazing period duration, or the sequence of harvest dates. Furthermore, the dates and the amount of inorganic $\mathrm{N}$ fertilizers application must be prescribed. The yearly quantity of $\mathrm{N}$ fertilizers prescribed to PASIM on each grid point is derived from the FAO agricultural statistics [Food and Agriculture Organization, $2002]$ in each country (see section 2.2.5). For the other management parameters, we built an optimization algorithm which determines a set of 'best' values at any given site, under a dual physiological and management constraint (see sections 2.2 .3 and 2.2.4).

\subsubsection{Climate and Weather}

[10] Meteorological input data are hourly temperature, precipitation, wind speed, air humidity and solar radiation values. These data, originally given as monthly fields at a resolution of $10^{\prime}$ by $10^{\prime}$ over the period $1900-2000$ from [Mitchell et al., 2004], were aggregated to $1^{\circ} \times 1^{\circ}$ resolution. Hourly fields were prepared by adding to the monthly means the 6-hourly variability from the ERA-15 reanalysis data [Gibson et al., 1997] for the year 1993. Each variable was linearly interpolated between the 6-hourly data except for the radiation, which was interpolated with a cubic function taking its maximum value at noon and equal to zero between the sunset and the sunrise. Such hourly variability is repeated identically each year when integrating the model over long periods, yet a more realistic solution than using a climatology of 6-hourly data, which would be too smooth compared to the variability of one particular year.

\subsubsection{Soil and Land Cover Information}

[11] Soil texture data come from the global data set of Webb et al. [2000] aggregated at $1^{\circ}$ by $1^{\circ}$ resolution. Field capacity, wilting point and bulk density come from the IGBP-DIS Selected Soil Characteristics global data set [Global Soil Data Task Group, 2000] at a resolution of $5^{\prime}$ by $5^{\prime}$. These data have been degraded to $1^{\circ} \times 1^{\circ}$ resolution by averaging the fields. The grassland vegetation cover of EU-15 countries was prescribed from the CORINE data sets [CORINE, 1995, 2000] which have an original spatial resolution of $250 \mathrm{~m}$. CORINE is based on analysis of LANDSAT and SPOT images for year 2000. For other regions of Europe we used the PELCOM land cover data [Mucher et al., 2000].

\subsubsection{Fractional Coverage of Cutting and Grazing,} and Optimal Animal Stocking Rate

[12] We assume that on a given grid point, grasslands are either cut or grazed, and do not consider mixed management (cutting and grazing). The simulated cutting events are a function of plant growth, and occur every 30 days or more. After 30 days of regrowth, a new cut is triggered whenever plant growth rate declines during 10 consecutive days.

[13] When grazing is simulated, it starts for shoot biomass values above a $200 \mathrm{~g} \mathrm{DM} \mathrm{m}^{-2}$ threshold. For a shoot biomass below that threshold, the simulated grazing stops 


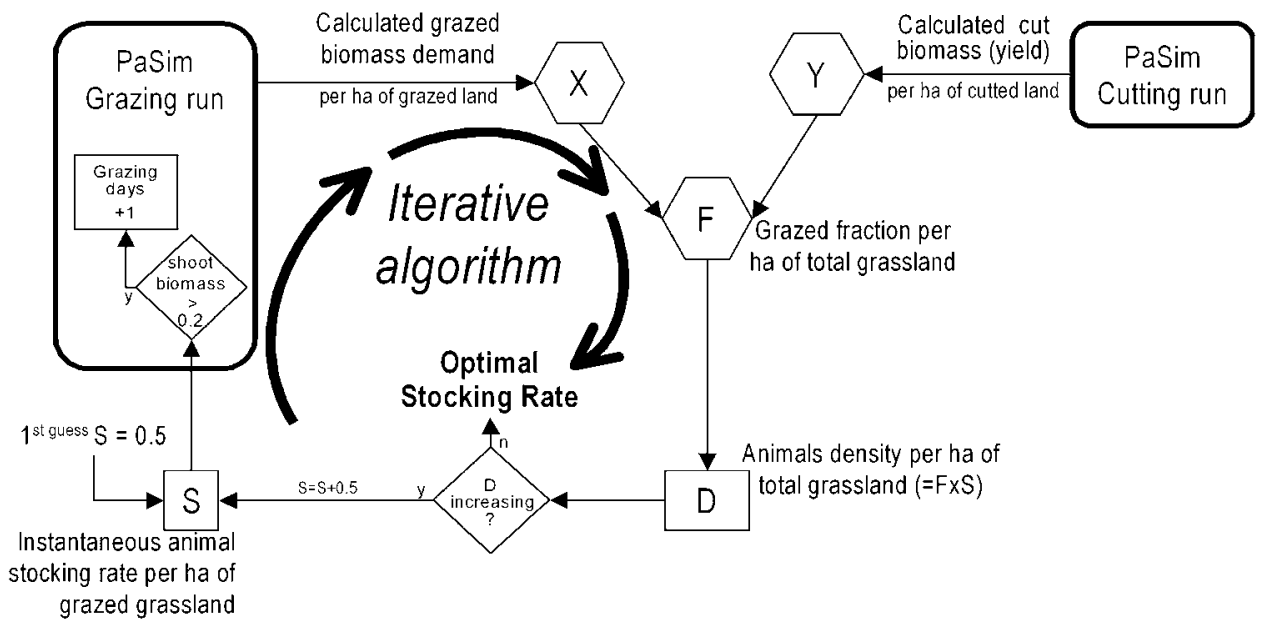

Figure 1. Diagram of the optimization procedure used for defining optimal animal stocking rate and optimal proportion of grazed grasslands.

and animals are assumed to be fed by herbage cut on the same grid point. To avoid numerical instability, grazing resumes when simulated shoot biomass becomes greater than $300 \mathrm{~g} \mathrm{DM} \mathrm{m}^{-2}$.

[14] We first performed two end-members run calculations, in which $100 \%$ of the grasslands are respectively grazed or cut. To obtain a 'realistic' European simulation, the two end-members need to be mixed according to a proportion $F$ of grazed versus cut grasslands on each grid point. The distribution of $F$ has been determined with an optimization algorithm (Figure 1) which allows to maximize the animal density $(D)$ in each grid pixel under the constraint that each grid point must remain self-sufficient in terms of animal feed production. Results from the $100 \%$ cut run define the potential yield $(Y, \mathrm{~kg} \mathrm{C}$ per ha of cut grasslands) that can be supplied by each grid point. The grazing run starts with a first guess value of the animal stocking rate (number of animals per ha of grazed grasslands, $S$ ) of 0.5 livestock unit per hectare (LSU ha ${ }^{-1}$ ). This value sets the number of days during which herbivores must be fed with cut herbage, and thus, the amount of cut herbage $(X)$ required per ha of grazed grasslands. With these two variables, we can calculate the fraction of grazed $(F)$ and cut $(1-F)$ grasslands as a function of the stocking rate. Multi- plying the stocking rate by the fraction of grazed grasslands gives the animal density per ha of grassland $(D)$ on each grid point. A maximum animal density, which is assumed in our case to correspond to optimal management conditions, is then calculated iteratively in the algorithm by increasing the input animal stocking rate until convergence is reached (Figure 1).

\subsubsection{Timing of Inorganic $\mathbf{N}$ Fertilizers Application}

[15] Immediately after each cut (cutting run), or every two months (grazing run), the grasslands may be fertilized with inorganic $\mathrm{N}$. We assume that $\mathrm{N}$ fertilizers are not applied by farmers when there is no plant growth. Thus the above predefined dates of fertilization are conditional on the ability of plants to assimilate nitrogen. For the same reason, the soil water content must not exceed the field capacity value.

\subsubsection{Amount of $\mathbf{N}$ Fertilizers}

[16] The FAO [Food and Agriculture Organization, 2002] produced country averaged statistics for fertilized areas and fertilizer amount (N, P and $\mathrm{K}$ ) given to various crop types. Figure 2 shows the proportion of fertilized grasslands and the mean rate of $\mathrm{N}$ fertilizers applied per unit area. In order to estimate the $\mathrm{N}$ fertilization intensity of each country, we perform two types of simulations. One in which both grazed and cut grasslands receive an annual amount of $\mathrm{N}$ fertilizers
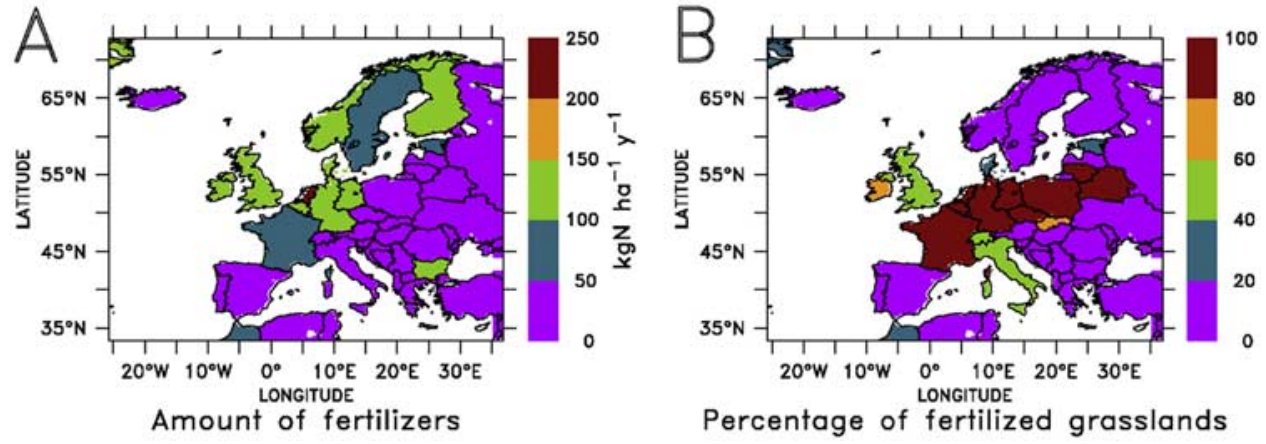

Figure 2. Amount of fertilizers and percentage of fertilized grasslands used for running PASIM (from IFA/IFDC/IPI/PPI/FAO and CORINE/PELCOM land cover data). 
equivalent to the national average for fertilized grasslands and another in which no fertilizers are applied. These two simulations are then combined using the proportion of fertilized grasslands in order to reflect the correct fertilization intensity. This constitutes a realistic scenario in terms of $\mathrm{N}$-fertilizers supply, which is used as a reference (REF) scenario. The fraction of fertilized grasslands at the national level is calculated by dividing fertilized areas (from FAO) by total (from CORINE) grasslands area. In the simulations with fertilization, the annual mean rate of inorganic $\mathrm{N}$ fertilizers is delivered into several applications, according to the method described in the section 2.2.4. We do not consider animal manure applications since relevant information is not available at European level. However, in the grazing simulations, dung and urine are accounted for, and assumed to be recycled in the soil.

[17] Furthermore, to test the sensitivity of greenhouse gas fluxes to N-fertilizers supply, we developed two additional scenarios. In one scenario (ZERO), no fertilization is considered and in the other (HIGH), we applied a high amount of $\mathrm{N}$ calculated in order to maximize the production of biomass. The calculation requires two runs. The first one, or N-saturated run, consists of applying nitrogen in excess (under the form of ammonium nitrate) at an arbitrary rate of $500 \mathrm{~kg} \mathrm{~N} \mathrm{ha}^{-1}$ at each application, and to store the values of carbon allocated into shoot biomass between two applications. The second one, or physiological optimum run, calculates the minimum supply of nitrogen giving the same amount of carbon allocated to shoot biomass as in the $\mathrm{N}$ saturated run. In other words, the physiological optimum run uses the minimum supply of fertilizer to reach the largest aboveground biomass production. Real-world management practices never try to reach, nor even to approach such physiological optimum conditions, which would have for side effects high $\mathrm{N}$ losses to the ground waters and to the atmosphere. Rather, $\mathrm{N}$ fertilizers are applied as a result of a compromise between physiological, economical and environmental considerations. We thus made the reasonable assumption to define the HIGH scenario by taking $30 \%$ of the annual $\mathrm{N}$-fertilizer amount corresponding to the physiological optimum run.

\subsection{Potential for $\mathrm{C}$ Sequestration and $\mathrm{Non}-\mathrm{CO}_{2}$ Gas Emissions}

\subsection{1. $\mathrm{CO}_{2}$ Budget}

[18] We perform a model spin run until asymptotic equilibrium pool sizes are reached starting from a nearly zero initial soil carbon and nitrogen pools. By construction, the equilibrium net carbon balance of each point taking into account losses of harvested carbon, or Net Biome Productivity (NBP), is equal to zero. We can only estimate a carbon sequestration potential from the mass balance of total soil carbon $C_{\text {soil }}$ during the spin up run, with an annual input flux, $I_{\text {soil }}$, and respiratory losses $R_{\text {soil }}=\frac{C_{\text {soil }}}{\tau}$ to the atmosphere, as given by

$$
\frac{d C_{\text {soil }}}{d t}=I_{\text {soil }}-\frac{C_{\text {soil }}}{\tau}
$$

[19] Integrating equation (1) with initial conditions $\mathrm{t}=0$; $C_{\text {soil }}(0)$ and constant input flux gives

$$
C_{\text {soil }}(t)=I_{\text {soil }} \tau\left(1-e^{-\frac{t}{\tau}}\right)+C_{\text {soil }}(0) e^{-\frac{t}{\tau}}
$$

[20] In the right hand part of equation (2), the first term corresponds to the mass of carbon accumulated by the grassland when reaching equilibrium conditions, the other corresponds to the decay of carbon formed in a previous ecosystem. We define the carbon sequestration potential starting from a zero soil carbon content $\left(\Pi_{\mathrm{C}, 0}\right)$ as the value of the term $I_{\text {soil }} l\left(1-e^{\frac{-t}{\iota}}\right)$ after a number of years equals to the mean residence time $(\mathrm{MRT}=\tau)$ of carbon in the soil,

$$
\Pi_{C, 0}=I_{\text {soil }} \tau\left(1-e^{-1}\right)
$$

[21] $\Pi_{C, 0}$ is the mass of carbon that could potentially be stored, on a finite time, by grasslands according to local pedo-climatic conditions (which influence $I_{\text {soil }}$ and $\tau$ ). $I_{\text {soil }}$ corresponds to the fraction of the net primary production (NPP) laid off to the soil (not used for forage, animal respiration, milk production or animal weight increase). The mean residence time $\tau$ is determined using the annual mean values of stocks and fluxes at the end of the simulation (when equilibrium is reached), $C_{\text {soil,eq }}$ and $R_{\text {soil,eq }}$ respectively, which gives

$$
\tau=\frac{C_{\text {soil }, e q}}{R_{\text {soil }, e q}}
$$

[22] The value of $\Pi_{\mathrm{C}, 0}$ is used as a convenient regional measure of potential carbon gains in front of non- $\mathrm{CO}_{2}$ gases loses (section 3.5.5).

\subsection{2. $\mathrm{CH}_{4}, \mathrm{~N}_{2} \mathrm{O}$ Emissions and Total GHG Budget Potential}

[23] Expressing the total GHG budget potential requires converting non- $\mathrm{CO}_{2}$ greenhouse species emissions into $\mathrm{CO}_{2}$-equivalents using their global warming potentials relative to the one of $\mathrm{CO}_{2}$ (GWP) [Intergovernmental Panel on Climate Change, 1995]. The 100-years time horizon GWPs of $\mathrm{N}_{2} \mathrm{O}$ and $\mathrm{CH}_{4}$ are 300 and 23 , on a mass equivalent basis (i.e., $1 \mathrm{kgN}-\mathrm{N}_{2} \mathrm{O}$ equates $127 \mathrm{kgC}-\mathrm{CO}_{2}$ and $1 \mathrm{kgC}-\mathrm{CH}_{4}$ equates $8.36 \mathrm{kgC}-\mathrm{CO}_{2}$ ). The $\mathrm{GHG}$ budget potential by the time $\tau$ can be defined as

$$
\Pi_{G H G, 0}=127 E_{N_{2} O} \tau+8.36 E_{C H_{4}} \tau-\Pi_{C, 0},
$$

where $E_{N 2 O}$ is the annual $\mathrm{N}_{2} \mathrm{O}$ emission (in $\mathrm{kgN}-\mathrm{N}_{2} \mathrm{O} \mathrm{ha}^{-1}$ $\mathrm{yr}^{-1}$ ) and $E_{\mathrm{CH}}$, the annual $\mathrm{CH}_{4}$ emission (in $\mathrm{kgC}_{-}-\mathrm{CH}_{4} \mathrm{ha}^{-1}$ $\mathrm{yr}^{-1}$ ) calculated from the equilibrium simulation results. However, the soil carbon content prior to the growth of a managed grassland is generally not zero. Thus, in order to investigate the sensitivity of the GHG budget potential to the initial soil carbon stock, we estimated the variable $\Pi_{\mathrm{GHG}, \mathrm{i}}$ for $\mathrm{i}=1 / 4,1 / 2$ and $3 / 4$ with initial soil carbon contents corresponding to one fourth, half and three fourths 


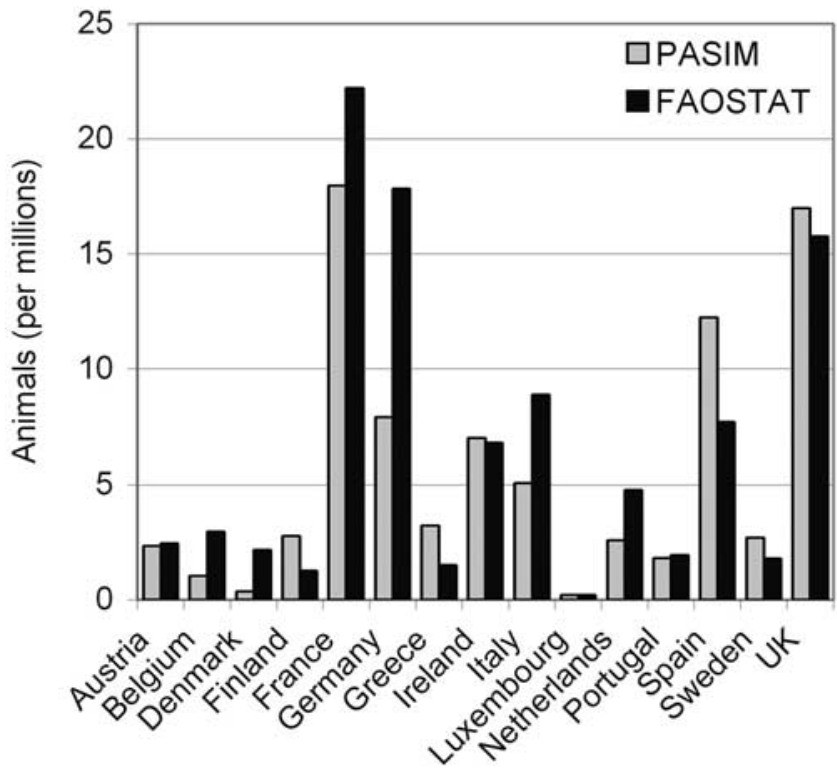

Figure 3. Number of animals in each country of EU-15 simulated by PASIM (grey columns) and estimated by the FAO (black columns).

of the MRT $\left(\mathrm{C}_{\text {soil }}(\tau / 4), \mathrm{C}_{\text {soil }}(\tau / 2)\right.$ and $\mathrm{C}_{\text {soil }}(3 \tau / 4)$ respectively). This is given by

$$
\Pi_{G H G, i}=(1-i)\left(127 E_{N_{2} O} \mathrm{O}+8.36 E_{C_{H_{4}}} \tau\right)-\Pi_{C, i}
$$

and

$$
\Pi_{C, i}=I_{\text {soil }} \tau\left(e^{-i}-e^{-1}\right) .
$$

\section{Results and Discussion}

\subsection{Number of Grazing Animals}

[24] Simulated European animal livestock numbers were compared with country averaged statistics (FAOSTAT data, 2004, available at faostat.fao.org). PASIM only considers cattle (the major contributors to enteric fermentation) while in reality grasslands do not support only cattle. Thus, to make a meaningful comparison between model output and statistics, we converted sheep data into cattle livestock using a ratio of 10 sheep for 1 cattle unit. For geographic Europe, we infer with PASIM that 137 millions cattle heads (Mheads) are supported by grasslands, a number which compares well with the FAO statistics giving an average of 174 Mheads over 1994-2003 (189 Mheads for 1994, 138 Mheads for $2003,-30 \%$ ), despite our simple management algorithm. For the EU-15, we simulate 84 Mheads while FAO reports 98 Mheads. Overall, there is a good agreement between model and data for country totals (Figure 3, RMSE = 3.4 Mheads; Mean Bias $=-0.9$ Mheads). The best agreement is found for temperate oceanic countries (France, Ireland and UK). There is however a significant model underestimation for Germany, Italy, and Netherlands (Figure 3). This may be explained by a large animal use of nonlocal forages (e.g., maize silage) and concentrated feed (e.g., soybean meals and cakes) in these countries. Our simulation treats each grid point as being self-sufficient and therefore, it is logical that PASIM underestimates the total number of animals when other feeds than herbage enter into livestock nutrition, as for dairy cows in particular, which systematically receive supplements to their diet. On the other hand, as the management module assumes that all the herbage must be used, we overestimate the cattle numbers in countries where grasslands are undergrazed and cattle fed mostly with herbage. This could explain the discrepancy between model and statistics for southern Europe countries such as Greece and Spain.

\subsection{Yield in Relation to the Supply of Fertilizers}

[25] Grassland yields simulated by PASIM were compared with in situ observations from the FAO network for Lowland Grasslands [Corrall, 1988]. This data set contains yield data for more than 20 experimental sites over Europe for 1 to 4 years duration over 1982-1986. All these sites were (strongly) fertilized weekly to ensure that growth was never inhibited by nutrient deficiency [Bouman et al., 1996]. Therefore the comparison has been made with the simulation of PASIM related to the HIGH scenario. Using output from this simulation, we calculate an average yield of $13.0 \pm 2.6 \mathrm{tDM} \mathrm{ha}^{-1} \mathrm{yr}^{-1}$ for the 20 sites in good agreement with the observations $\left(12.4 \pm 3.1 \mathrm{tDM} \mathrm{ha}^{-1} \mathrm{yr}^{-1}\right)$. The claim we can make from this comparison is not that PASIM has a realistic yield all over Europe, but that the modeled yield reacts realistically to high nitrogen fertilizer inputs. This suggests that growth is well simulated by PASIM and that our automatic management module simulated a realistic magnitude of the cut herbage.

\subsection{Cut Grasslands}

3.3.1. Carbon Fluxes

[26] We calculated the NPP and the grass yield distribution over Europe (Figures $4 \mathrm{c}$ and $4 \mathrm{a}$ ). The annual NPP ranges from very low values to $12 \mathrm{tC} \mathrm{ha}{ }^{-1} \mathrm{yr}^{-1}$. The yield to NPP ratio that we call NPP use efficiency, or NPPUE, has a spatial mean value of $0.44\left(\mathrm{R}^{2}=0.86\right.$, Figure 5). The seasonal cycle of Europe's average NPP, yield, soil respiration and NEE is presented in Figure 6a for the cut simulations. These figures show how cuts dramatically impact the $\mathrm{C}$ fluxes. On average, the growth starts slowly around day 50 of the year and significantly increases around day 100 .

\subsection{2. $\mathrm{N}_{2} \mathrm{O}$ Emissions and Cutting}

[27] The $\mathrm{N}_{2} \mathrm{O}$ emissions from soils vary from low values to $2.3 \mathrm{kgN} \mathrm{ha}^{-1} \mathrm{yr}^{-1}$ (mean value of $0.5 \mathrm{kgN} \mathrm{ha}^{-1} \mathrm{yr}^{-1}$, Figure 4e). The amount of fertilizer supplied explains only $10 \%$ of the $\mathrm{N}_{2} \mathrm{O}$ emissions variations. A linear regression of the modeled $\mathrm{N}_{2} \mathrm{O}$ emissions vs. the amount of fertilizers gives a slope of $0.9 \times 10^{-2}$ for the slope and an intercept of $0.43 \mathrm{kgN} \mathrm{ha}^{-1} \mathrm{yr}^{-1}$ (Figure 7a). The relationship between $\mathrm{N}_{2} \mathrm{O}$ emission and $\mathrm{N}$-fertilizers input as calculated by PASIM has been compared with emission factors regressed from in situ flux data by Bouwman [1996] and Freibauer and Kaltschmitt [2003]. The slope obtained with the simulation model is far lower than those empirically determined 

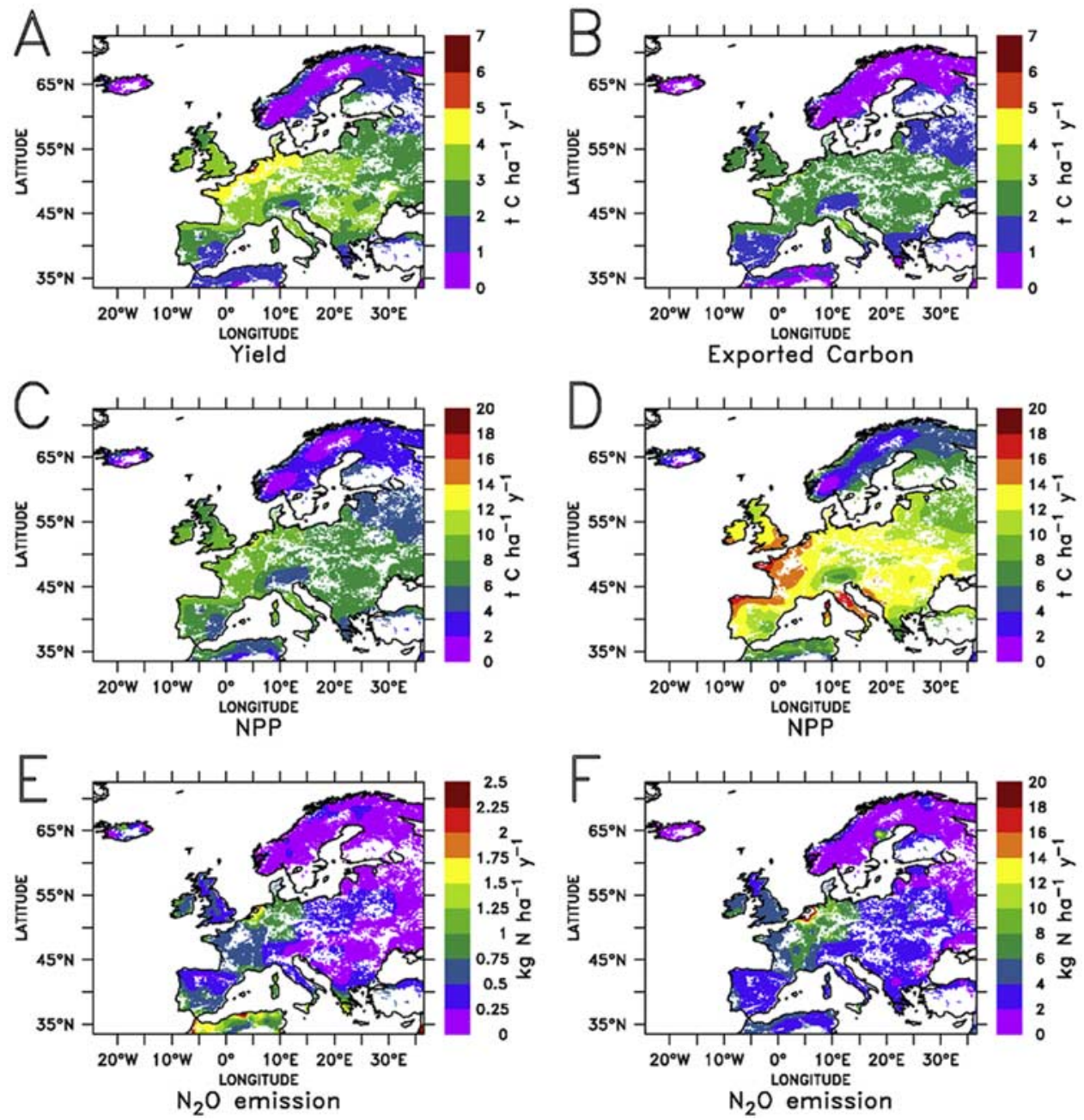

Figure 4. Simulated annual amount of exported carbon (A and $\left.\mathrm{B}, \mathrm{tC} \mathrm{ha}^{-1} \mathrm{yr}^{-1}\right)$, annual NPP (C and D, tC $\mathrm{ha}^{-1} \mathrm{yr}^{-1}$ ) and annual $\mathrm{N}_{2} \mathrm{O}$ emissions ( $\mathrm{E}$ and $\mathrm{F}, \mathrm{kgN} \mathrm{ha}^{-1} \mathrm{yr}^{-1}$ ) for the Cut Grasslands and Grazed Grasslands runs of the REF scenario, respectively.

by Bouwman (0.0125), and Freibauer and Kaltschmitt (0.015). The modeled intercept is also significantly lower than in the two above studies. These discrepancies may be explained by the fact that the amount of fertilizer applied in our simulations varies from 15 to $240 \mathrm{kgN} \mathrm{ha}^{-1} \mathrm{yr}^{-1}$, a restricted range compared to those reported by Bouwman [1996] and by Freibauer and Kaltschmitt [2003].

\subsection{Grazed Grasslands}

\subsubsection{Fertilizer Control on Animal Density and Carbon Fluxes}

[28] PASIM calculates the number of days during which animals can graze on a plot, the instantaneous animal stocking rate and the daily amount of biomass removed by grazing. In Figures $8 \mathrm{a}, 8 \mathrm{~b}$ and $8 \mathrm{c}$ we show maps of the first day and the total duration of grazing, together with the annual mean annual stocking rate (instantaneous stocking rate times the fraction of grazing days per year). The grazing period duration varies from 0 to 180 days per year and so does the annual mean stocking rate ranging from 0 to
2.1 LSU ha $\mathrm{Lr}^{-1} \mathrm{yr}^{-1}$. Cattle intake is nearly proportional to annual mean stocking rate.

[29] As shown in Figure 4d, the NPP of grazed grasslands varies from very low values up to $19 \mathrm{tC} \mathrm{ha}^{-1} \mathrm{yr}^{-1}$. The spatial distribution of the NPP under grazing shows similar patterns than under the cut scenario (Figure $4 \mathrm{c}$ ). The amount of carbon 'exported' out of the grassland (EC) is equal to the sum of animal respiration, weight increase and milk production and was compared to the NPP (Figure 5). The NPPUE has a spatial mean value of $0.2\left(\mathrm{R}^{2}=0.92\right.$, Figure 5) and shows approximately the same spatial patterns than in the cut scenario (not shown). The continental-scale averaged seasonal cycles of NPP, EC, soil respiration and NEE (without the animal respiration) are shown in Figure $6 \mathrm{~b}$. The NPP of grazed grasslands has a different response to fertilizers supply than that of cut grasslands. This results in NPP of pastures being 56\% higher than the one of meadows over Europe. In the REF scenario, both cut and grazed grasslands receive the same amount of fertilizers (see section 2.2.5). Under grazing, a large fraction of the supplied $\mathrm{N}$ is recycled as urine and dung, while $\mathrm{N}$ recycling 


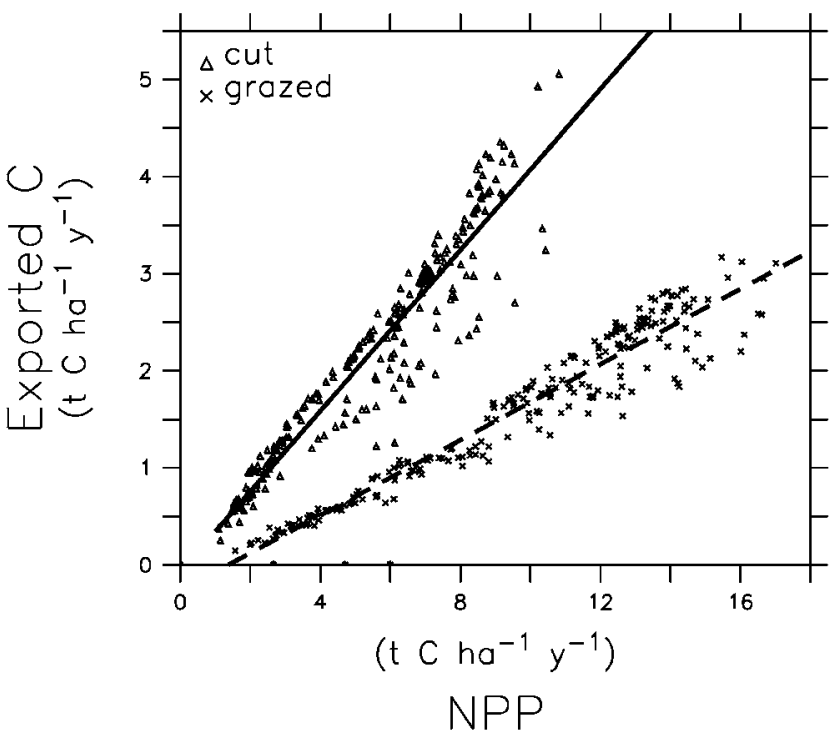

Figure 5. Harvested carbon ( $\mathrm{tC} \mathrm{ha} \mathrm{ha}^{-1} \mathrm{yr}^{-1}$ ) versus NPP (tC $\mathrm{ha}^{-1} \mathrm{yr}^{-1}$ ) for the Cut Grasslands (triangles and bold line for the regression) and Grazed Grasslands (crosses and dashed line for the regression) runs. $\mathrm{R}^{2}$ values are for the Cut and Grazed grasslands 0.86 and 0.92 , respectively.

is much lower under cutting conditions, a large fraction of the $\mathrm{N}$ supplied being exported in the cut herbage [Scholefield et al., 1991]. Therefore, for the same $\mathrm{N}$ supply, grazing enhances the N content of the ecosystem and its NPP when compared to cutting. Soil respiration is also greater for pastures than for meadows $(87 \%)$. Domestic herbivores return the nondigestible $\mathrm{C}$ (between 20 and $40 \%$ of the ingested carbon [Soussana et al., 2004]) to the soil as dung. This extra source of carbon for soil decomposition, as well as a higher NPP, both contribute to increase soil respiration under grazing compared to cutting.

3.4.2. $\quad \mathrm{N}_{2} \mathrm{O}$ Emissions and Grazing

[30] The $\mathrm{N}_{2} \mathrm{O}$ emissions by fertilized soils are about 9 times higher with grazing than with cutting. This is due to the animal's dung and urine being laid off to the soil. Soil $\mathrm{N}_{2} \mathrm{O}$ emissions vary from low value up to $25 \mathrm{kgN} \mathrm{ha}^{-1} \mathrm{yr}^{-1}$
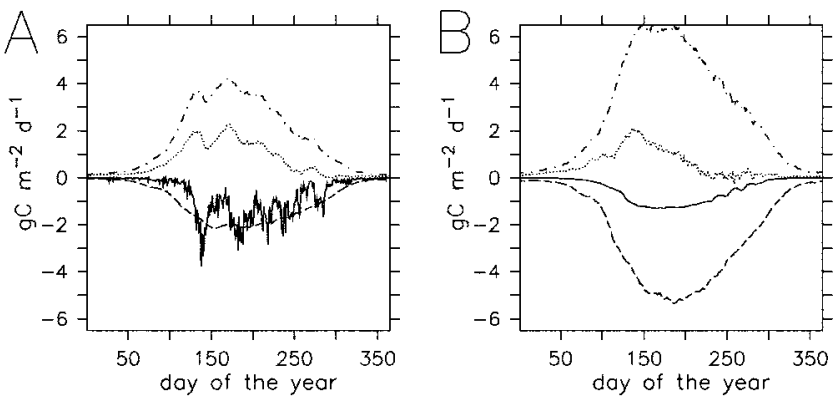

Figure 6. European averages of seasonal cycles of NPP (dash-dotted line), exported carbon (solid line), soil respiration (dashed line) and NEE (dotted line) for (a) the Cut Grasslands scenario and (b) the Grazed Grasslands scenario, expressed in $\mathrm{gC} \mathrm{m}^{-2} \mathrm{~d}^{-1}$.
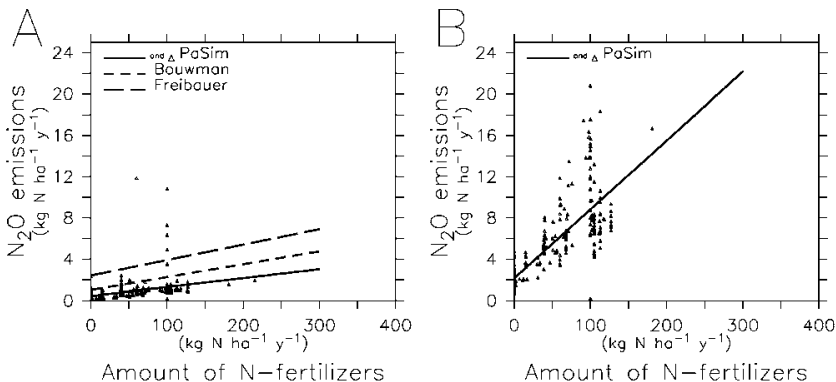

Figure 7. Relation between $\mathrm{N}_{2} \mathrm{O}$ emission $\left(\mathrm{kgN} \mathrm{ha}^{-1}\right.$ $\mathrm{yr}^{-1}$ ) and amount of fertilizers applied for (a) the Cut Grasslands run and (b) the Grazed grasslands run. $\mathrm{R}^{2}$ values are 0.10 for the Cut grasslands and 0.53 for the grazed grasslands.

(mean value of $3.3 \mathrm{kgN} \mathrm{ha}^{-1} \mathrm{yr}^{-1}$, Figure 4f). We found that $\mathrm{N}_{2} \mathrm{O}$ emissions from pastures are correlated with the amount of fertilizers delivered to each grid point to increase productivity $\left(\mathrm{R}^{2}=0.53\right.$ ) (Figure $7 \mathrm{~b}$ ). The linear regression of $\mathrm{N}_{2} \mathrm{O}$ emissions vs. fertilizer inputs is significant with a slope of 0.07 and an intercept of $2.1 \mathrm{kgN} \mathrm{ha}^{-1} \mathrm{yr}^{-1}$. Therefore the simulated $\mathrm{N}_{2} \mathrm{O}$ emission factor for the same $\mathrm{N}$ fertilizer supply is far greater under grazing than under cutting.

3.4.3. Animal $\mathrm{CH}_{4}$ Emissions by Grazing Livestock

[31] As expected, methane emissions from pastures reflect the annual stocking rates in each region. We simulate a mean

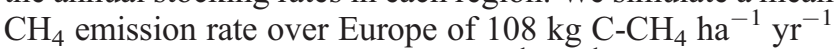
corresponding to $130 \mathrm{~kg} \mathrm{CH}_{4}$ head $^{-1} \mathrm{yr}^{-1}$, higher than the commonly accepted IPCC value for dairy cattle in Western Europe of $100 \mathrm{~kg} \mathrm{CH}_{4}$ head $^{-1} \mathrm{yr}^{-1}$ [Intergovernmental Panel on Climate Change, 1997]. However, new in situ estimates during the GREENGRASS project [Pinarès-Patino et al., 2007] also suggest higher mean $\mathrm{CH}_{4}$ emissions rates $(145 \mathrm{~kg}$ $\mathrm{CH}_{4}$ head $^{-1} \mathrm{yr}^{-1}$ ) for grazing cattle.

\subsection{Toward Realistic Simulations: Combining Cutting and Grazing}

[32] The parameter used to mix the end-member simulations of grazing and cutting is the modeled proportion $F$ of grazed land in each grid point (see section 2.2.3). The value of $F$ is calculated by the optimization procedure (see Figure 1) and its spatial distribution is given in Figure 9. It is seen that the fraction of grazed lands ranges from very low values in Nordic countries $(<10 \%)$, to intermediate over Alpine regions $(15-30 \%)$, and reaches its maximum $(\approx 45 \%)$ in Western France, Netherlands and the Northern Iberian Peninsula.

\subsubsection{Net Primary Productivity Versus Remote Sensing of FPAR}

[33] The NPP distribution for the REF simulation combining grazing with cutting is shown in Figure 10a. It is very difficult to independently validate such modeled NPP spatial patterns, given the scarceness of field NPP observations, and given a number of measurement gaps for belowground components of NPP such as the autotrophic (root) respiration. 

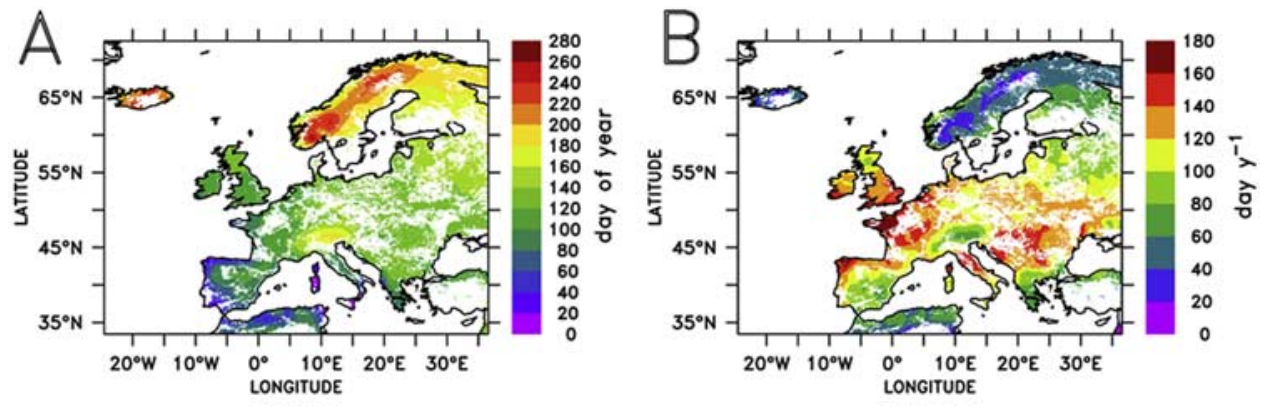

Start of Grazing
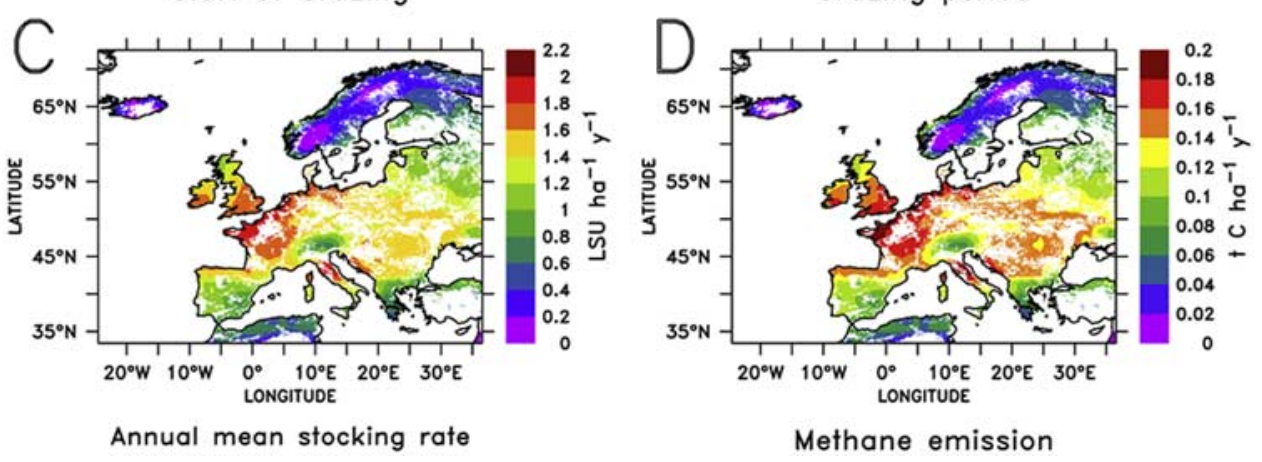

Figure 8. (a) First day of grazing (day of the year), (b) number of grazed days per year (days), (c) annual mean stocking rate (LSU ha ${ }^{-1} \mathrm{yr}^{-1}$ ) and (d) annual methane emissions ( $\mathrm{tC} \mathrm{ha}^{-1} \mathrm{yr}^{-1}$ ) for the Grazed Grasslands run of the REF scenario.

[34] Instead, we have used an indirect validation method based on comparisons with remotely sensed fields of leaf area index (LAI) and fraction of absorbed photosynthetically active radiation (FPAR), both from EOS-TERRAMODIS for year 2002 [Myneni et al., 2002] established at $1-\mathrm{km}$ resolution every 10 days. The mean FPAR and LAI over grassland grid points were calculated using the CORINE and PELCOM land cover information (a $1 \mathrm{~km}$ MODIS datum is picked up only when the corresponding grassland coverage is $100 \%$ ). The FPAR field is diagnosed from the PASIM output using

$$
F P A R=1-e^{-b L A I},
$$

with $b=0.6$. We compare the seasonal cycle of modeled and remotely sensed LAI averaged over Europe in Figure 11 (comparison of FPAR data showed similar results). We verified that the seasonality of the LAI from MODIS has a different phase for grasslands than for other vegetation types (see Figure 11), indicating that satellite data contain useful information to specifically validate grassland phenology, beyond the evident observation that the vegetation gets greener in summer and remains dormant in winter. One can see that the simulated LAI phase and amplitude agree well with the remote sensing data. The linear regression slope from all grid points is 0.90 and the intercept $0.24 \mathrm{~m}^{2} \mathrm{~m}^{-2}\left(\mathrm{R}^{2}=0.96\right)$. The growth onset occurs in March, maximal LAI values in July and senescence occurs later in the season. Note that wintertime LAI values do not reach zero in regions with mild climate conditions where grasslands photosynthesize all year round. The mean
LAI $\left(\approx 0.6 \mathrm{~m}^{2} \mathrm{~m}^{-2}\right)$ inferred in PASIM is however slightly lower than the one of MODIS $\left(\approx 0.9 \mathrm{~m}^{2} \mathrm{~m}^{-2}\right)$. Note also that in MODIS, regions above $53^{\circ} \mathrm{N}$ in latitude are not well measured in winter months $(25 \%$ satellite coverage in January, 50\% in December and February), yielding to a likely overestimation of the remotely sensed LAI.

\subsubsection{Total Exported Carbon}

[35] The map of amount of $\mathrm{C}$ exported from grasslands (EC) altogether by harvests, animal respiration and animal

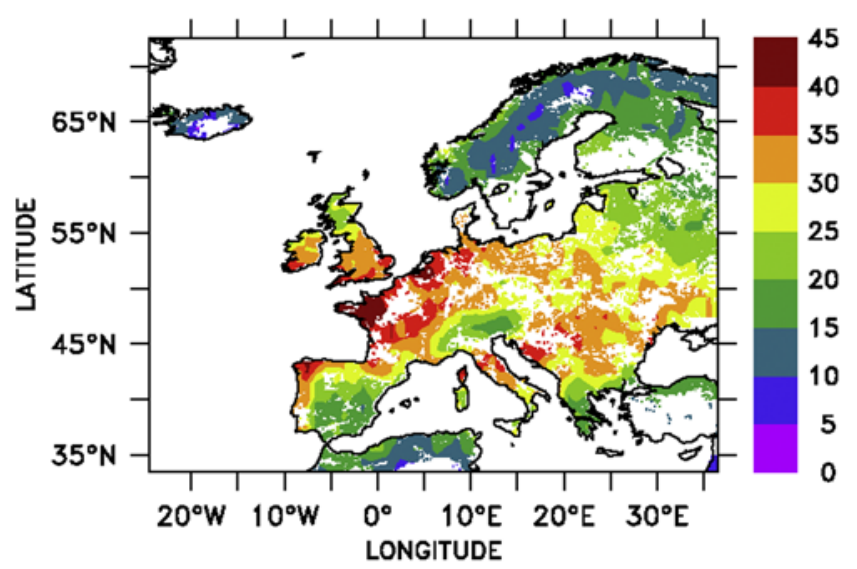

\section{Grazed grassland}

Figure 9. European distribution of the proportion of grazed grasslands (percent of the total grassland area) in the REF scenario of PASIM. 

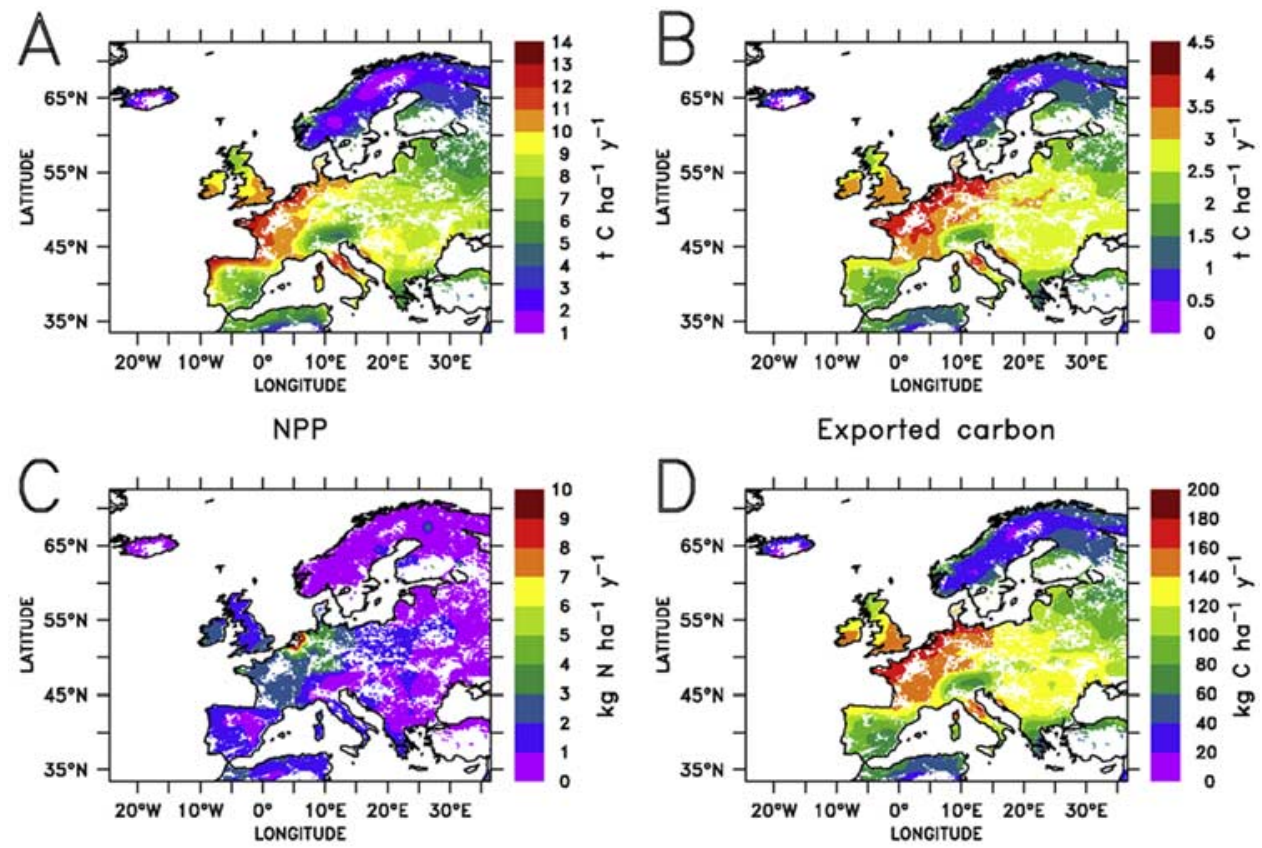

Exported carbon
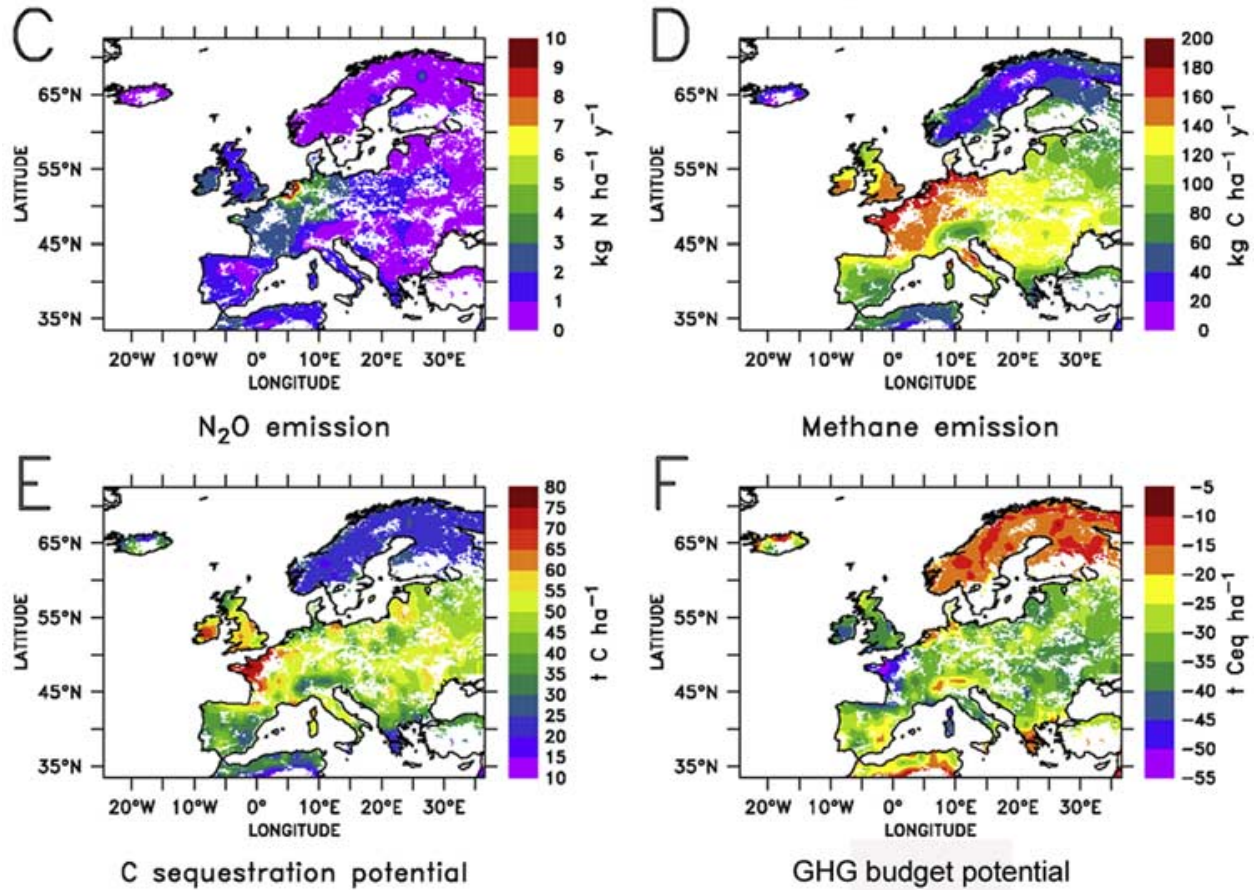

Figure 10. European distribution of (a) the Net Primary Production $\left(\mathrm{tC} \mathrm{ha}^{-1} \mathrm{yr}^{-1}\right)$, (b) the exported carbon $\left(\mathrm{tC} \mathrm{ha} \mathrm{hr}^{-1}\right)$, (c) the annual nitrous oxide emission $\left(\mathrm{kgN} \mathrm{ha}^{-1} \mathrm{yr}^{-1}\right)$, (d) the annual methane emission $\left(\mathrm{kgC}_{-} \mathrm{CH}_{4} \mathrm{ha}^{-1} \mathrm{yr}^{-1}\right)$, (e) the potential of carbon sequestration $\left(\mathrm{tC} \mathrm{ha}^{-1}\right.$ ) and (f) the GHG budget potential (tCeq $\mathrm{ha}^{-1}$ ) simulated with the REF scenario of PASIM.

products is shown in Figure 10b. The average carbon fluxes over both cut and grazed grasslands in the combined scenario are summarized in Figure 12. Per hectare of grassland cover, the cut grasslands contribute to 61 and $78 \%$ of the total NPP and of the total EC, respectively. The yield contributes the largest share of the total EC, being 3.6 times larger than the sum of animal respiration at grazing, milk and methane emissions. Even though the cut grasslands have the largest share of the NPP, the cut and grazed lands contribute equally to the soil respiration flux. This is not surprising, since the cut grasslands also have a larger harvest index, which reduces the fraction of the assimilated carbon that is respired belowground.

\subsubsection{Total Soil $\mathrm{N}_{\mathbf{2}} \mathrm{O}$ Emissions}

[36] The mean European soil $\mathrm{N}_{2} \mathrm{O}$ flux reaches $1.3 \mathrm{~kg} \mathrm{~N}$ $\mathrm{ha}^{-1} \mathrm{yr}^{-1}\left(0.16 \mathrm{t} \mathrm{Ceq} \mathrm{ha}^{-1} \mathrm{yr}^{-1}\right.$, Figure 10c) The emissions of $\mathrm{N}_{2} \mathrm{O}$ are dominated by grazed $\left(0.9 \mathrm{~kg} \mathrm{~N} \mathrm{ha}^{-1} \mathrm{yr}^{-1}\right)$ rather than by cut $\left(0.4 \mathrm{~kg} \mathrm{~N} \mathrm{ha}^{-1} \mathrm{yr}^{-1}\right)$ grasslands owing to the additional input of animal's dejection.

\subsubsection{Total Animal Densities and $\mathrm{CH}_{4}$ Emissions}

[37] The simulated animal density per hectare of grasslands cover reaches $1.0 \mathrm{LSU} \mathrm{ha}^{-1}$ on average. The carbon flux map which best correlates with animals density is the exported carbon (Figure 10b), suggesting that the carrying capacity of pasture relates to the productivity of the grasslands that are cut to provide herbage in winter and not only to the NPP of the pasture during the grazing.

[38] The cattle $\mathrm{CH}_{4}$ emissions mapped in Figure 10d are to total emissions, i.e., include $\mathrm{CH}_{4}$ emitted by indoor animals consuming forage harvested from the cut plots. The $\mathrm{CH}_{4}$ emissions distribute almost proportionally to animal densities, around an average value of $98 \mathrm{~kg} \mathrm{C}-\mathrm{CH}_{4}$ $\mathrm{ha}^{-1} \mathrm{yr}^{-1}\left(0.8 \mathrm{tCeq} \mathrm{ha}^{-1} \mathrm{yr}^{-1}\right)$. Maximum emissions reach 


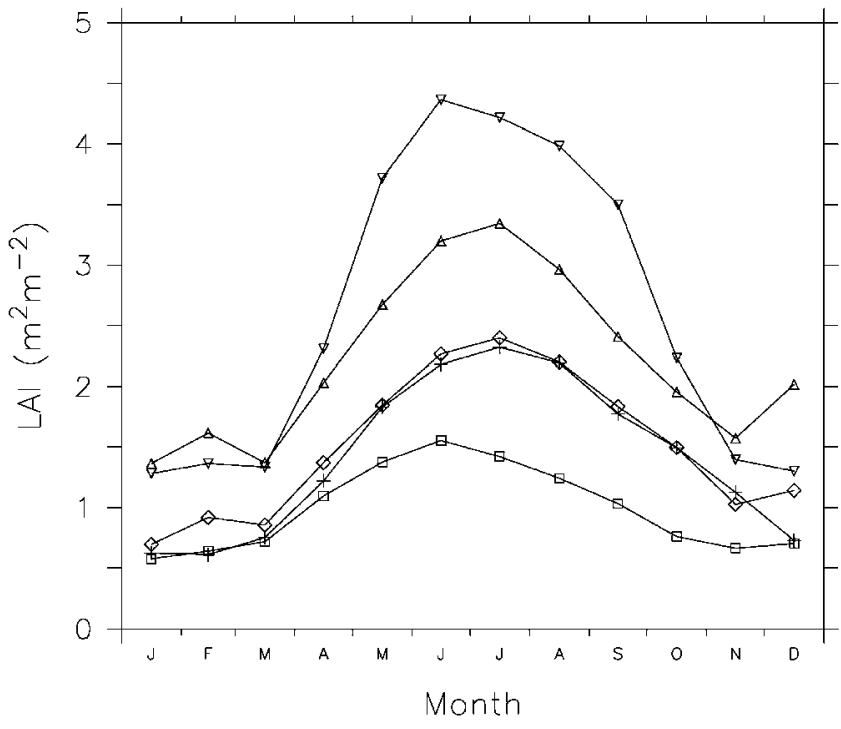

Figure 11. Seasonal cycle of the LAI variable from PASIM runs (pluses) and from MODIS for grasslands (diamonds), C3 crop (squares), broad-leaved summergreen forests (point-down triangles) and needle-leaved evergreen forests (point-up triangles).

$190 \mathrm{kgC}-\mathrm{CH}_{4} \mathrm{ha}^{-1} \mathrm{yr}^{-1}$ in Britany, Netherlands and Northern Germany.

\subsubsection{Total Carbon Sequestration and GHG Budget Potentials}

[39] The carbon sequestration potential defined by equation (3) varies from 9 to $75 \mathrm{tC} \mathrm{ha}^{-1} \mathrm{yr}^{-1}$ (Figure 10e). However, the GHG sources of soil $\mathrm{N}_{2} \mathrm{O}$ and cattle $\mathrm{CH}_{4}$ emissions, expressed in carbon equivalents during the period of sequestration offsets $34 \%$ of the carbon sequestration potential value. In carbon equivalents, the GHG budget potential $\left(\Pi_{\mathrm{GHG}, 0}\right)$, which assumes a zero value for initial soil carbon stock, is a sink (Figure 10f) everywhere with a mean European value of $-27 \mathrm{t} \mathrm{Ceq} \mathrm{ha}^{-1}$. The simulated GHG budget potential strongly varies with the initial soil carbon stock. Comparing different initial soil carbon stocks (equations (6) and (7)) lower than the equilibrium value, we conclude that the carbon sink $\left(\Pi_{C, i}\right)$ always remains larger than the non- $\mathrm{CO}_{2}$ trace gas emissions. Despite this, increasing soil initial stock from $\mathrm{C}_{\text {soil }}(0.25 \tau)$ to $\mathrm{C}_{\text {soil }}(0.75 \tau)$ increases non- $\mathrm{CO}_{2}$ emissions from 46 up to $52 \%$ of the carbon sequestration potential, thus reducing the role of grasslands as a net potential sink of radiative forcing. In contrast, if one would assume that all grassland soils are at their equilibrium carbon content, the model would predict grasslands to be sources of radiative forcing due to non $\mathrm{CO}_{2}$ gases emissions (data not shown). 3.5.6. Sensitivity of GHG Budgets to the Supply of Fertilizers

[40] $\mathrm{N}$ fertilization enables to increase NPP in the REF scenario by on average $7 \%$ compared to the ZERO scenario where no fertilizers are used. Small increases in NPP between ZERO and REF are obtained for regions where no or little fertilizers are applied in the REF scenario (for example in Eastern Europe, Figure 13a). The NPP of the
HIGH scenario is $18 \%$ higher than that in the REF scenario (Figure 13b). Therefore the amount of exported C (EC) through yield, animal respiration or milk production is also increased by $\mathrm{N}$ fertilization. The response of EC to fertilization is proportionally higher than the one of NPP $(15 \%$ and $28 \%$ of increase, from the ZERO to REF scenario and from the REF to HIGH scenario respectively). So, the supply of $\mathrm{N}$ fertilizers increases not only the NPP but also the NPP use efficiency. Consequently, the input of carbon to the soil is only $3 \%$ higher in the REF scenario than in the ZERO scenario and $11 \%$ higher in the HIGH scenario than in the REF scenario (Figures $13 \mathrm{c}$ and $13 \mathrm{~d}$, respectively). The potential of $\mathrm{C}$ sequestration shows similar response, a $5 \%$ increase from the ZERO to the REF scenario and a $10 \%$ increase from the REF to the HIGH scenario.

[41] If $\mathrm{N}$ fertilization increases the carbon sequestration potential, it also increases $\mathrm{N}_{2} \mathrm{O}$ and $\mathrm{CH}_{4}$ emissions (the latter since the grasslands can support more animals). Europe's mean $\mathrm{N}_{2} \mathrm{O}$ emission goes from $0.9 \mathrm{kgN} \mathrm{ha}^{-1} \mathrm{yr}^{-1}$ in the ZERO scenario to $4.3 \mathrm{kgN} \mathrm{ha}^{-1} \mathrm{yr}^{-1}$ in the HIGH scenario (to compare with $1.3 \mathrm{kgN} \mathrm{ha}^{-1} \mathrm{yr}^{-1}$ of $\mathrm{N}_{2} \mathrm{O}$ emissions in the REF scenario). Note however that, unlike the one of carbon fluxes, the response of $\mathrm{N}_{2} \mathrm{O}$ emissions to increasing supply of $\mathrm{N}$ fertilizers is far from uniform over the whole continent (Figures 13e and 13f). Cattle emit 15\% more $\mathrm{CH}_{4}$ from the ZERO to the REF scenario and $26 \%$ more from the REF to the HIGH scenario (Figures $13 \mathrm{~g}$ and 13h).

[42] Overall, in carbon equivalents, the non- $\mathrm{CO}_{2}$ gases emissions offset $28 \%$ of the carbon sequestration potential $\left(\Pi_{\mathrm{GHG}, 0}\right)$ in the ZERO scenario and $47 \%$ of $\Pi_{\mathrm{GHG}, 0}$ in the $\mathrm{HIGH}$ scenario. For all scenarios, the potential GHG budget remains a sink, but this sink gets reduced with higher fertilizer supplies. We infer a $3 \%$ and $8 \%$ reduction from the ZERO to the REF scenario and from the REF to the HIGH scenario, respectively (Figures $13 \mathrm{i}$ and $13 \mathrm{j}$ ). Increasing initial soil carbon values from $\mathrm{C}_{\text {soil }}(0.25 \tau)$ to $\mathrm{C}_{\text {soil }}(0.75 \tau)$ increases the difference in $\Pi_{\mathrm{GHG}, \mathrm{i}}$ between the

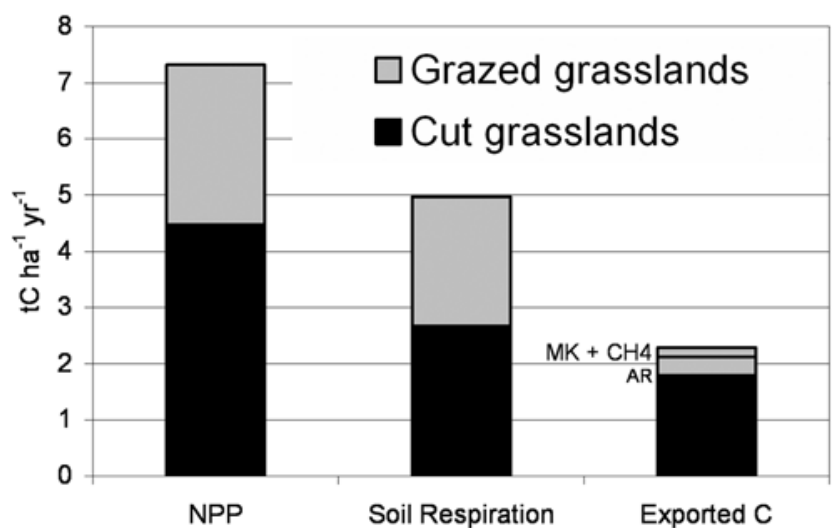

Figure 12. Carbon fluxes obtained when combining Cut and Grazed grasslands runs. All fluxes are positive by convention, although they can be uptake or release of atmospheric carbon. MK is the amount of carbon in milk, $\mathrm{CH}_{4}$ is the animal's methane emissions, and AR is the small term of animal respiration. Animal returns affect soil respiration. 

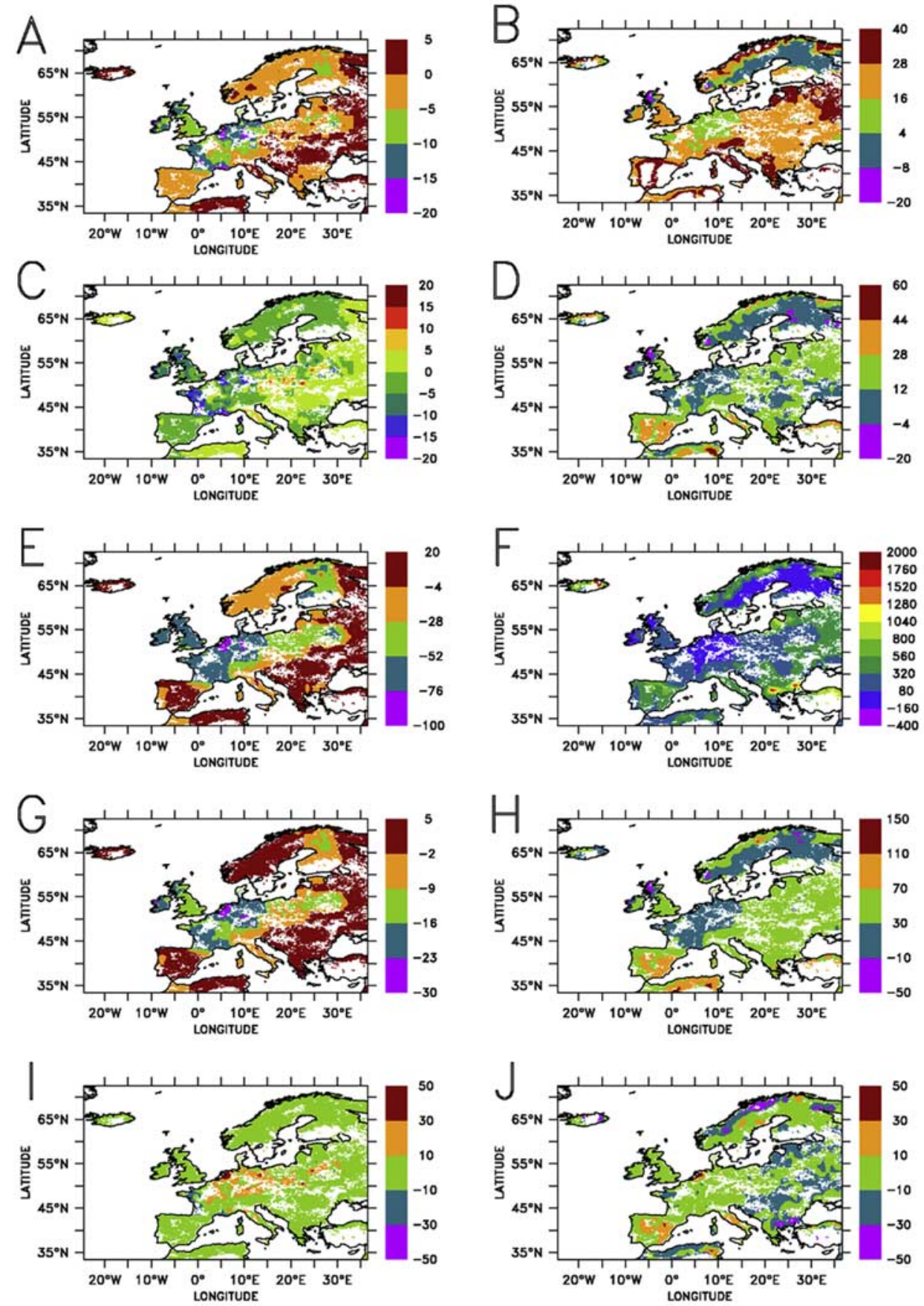

Figure 13. Relative differences (\%) between the REF and the ZERO scenario (on the left, calculated as $\left[\mathrm{val}_{\mathrm{ZERO}}-\mathrm{val}_{\mathrm{REF}}\right] / \mathrm{val} \mathrm{REF}_{\mathrm{REF}}$ ) and between the HIGH and the REF scenario (on the right, calculated as $\left[\mathrm{val}_{\mathrm{HIGH}}-\mathrm{val}_{\mathrm{REF}}\right] / \mathrm{val}_{\mathrm{REF}}$ ) for (a, b) the NPP, (c, d) annual carbon input to the soil, (e, f) $\mathrm{N}_{2} \mathrm{O}$ emissions, $(\mathrm{g}, \mathrm{h}) \mathrm{CH}_{4}$ emissions, and (i, j) GHG budget potential.

ZERO and REF scenarios and between the REF and HIGH scenarios $(10 \%$ and $32 \%$ of reduction, respectively when starting from $\left.\mathrm{C}_{\text {soil }}(0.75 \tau)\right)$.

\section{Conclusions}

[43] We provide a new estimate of the net radiative forcing fluxes of European grasslands, based upon a pro- cess-oriented model. The model accounts explicitly for edaphic, climatic and potential management variability over Europe. The distribution of management practices (grazing vs. cutting, cut events, animal density) is simulated to match biological constraints rather than economic ones. We assumed that the management in each grid point reflects the capacity of grasslands to optimally sustain animals through grazing and feeding on locally harvested forage. 
In other words, we assume that macro and micro-economical and cultural forces are of second order compared to biological constraints. These assumptions may seem provocative, but, surprisingly enough, they result into realistic values of the LAI seasonal patterns, of the amount of harvested forage, of livestock numbers, of $\mathrm{CH}_{4}$ emissions and to some extent of the $\mathrm{N}_{2} \mathrm{O}$ emission dependency on $\mathrm{N}$ fertilizers.

[44] The grasslands in Europe have a specific LAI seasonal dynamic compared to other ecosystems, as revealed by analysis of EOS-Terra-MODIS satellite data. The LAI dynamics are also well captured by our model, suggesting that phenology is rather realistic after the improvements which have been made concerning leaf turnover [Vuichard et al., 2007] to match site flux and biomass data. In addition, the fact that the modeled yield compares well with data from 20 harvested sites suggests that the magnitude and frequency of cuts is adequately simulated by the 'automatic management' rules.

[45] At the European level, $\mathrm{CH}_{4}$ emissions are directly proportional to animal numbers. The simulated cattle carrying capacity was found to be in fair agreement with country statistics. For soil $\mathrm{N}_{2} \mathrm{O}$ emissions, we calculated an emission factor for cut grasslands lower than values from previous field studies [Bouwman, 1996; Freibauer and Kaltschmitt, 2003] but on a restricted range of $\mathrm{N}$ fertilizers than in these field studies.

[46] In general, we believe that the main discrepancies between model and observations reflect management uncertainties rather than physiological processes uncertainties. Our management scheme assumes an optimal grassland use, whereas economic drivers are quite strong (subsidies, cost of fertilizers, revenue of animals products...). We could not simulate under-used grasslands for instance, although these are common in mountain regions [Marriott et al., 2004].

[47] We conclude that when nitrogen fertilizers are added, NPP increases as the NPP use efficiency (as defined by the ratio of exported carbon to NPP). Consequently, differences between fertilizers scenarios (ZERO, REF, HIGH) regarding the amount of carbon delivered to the soil are lower than for NPP. This behavior has important implications for the carbon sequestration potential which is only $5 \%$ higher in the REF scenario than in the ZERO one (and 10\% higher in the HIGH scenario than in the REF one). Note that the sequestration potential is defined as the total amount of carbon that grasslands could store when planted on bare soils. The actual NBP should be much lower given realistic values for soil carbon in grasslands.

[48] During the time period required to reach the amount of carbon that can potentially be stored after planting, $\mathrm{N}_{2} \mathrm{O}$ and $\mathrm{CH}_{4}$ emissions are initially lower (in $\mathrm{CO}_{2}$ equivalents) than $\mathrm{CO}_{2}$ sinks. However, as the soil carbon stocks tend toward their equilibrium value, non- $\mathrm{CO}_{2}$ gases emissions turn the radiative forcing balance to a net source. This result is independent of the nitrogen fertilizer status, even though if, per ton of sequestered carbon, a fertilized grassland would still emit more non- $\mathrm{CO}_{2}$ gases than a nonfertilized one. Thus the GHG budget of grasslands may shift from a sink to a source for any fertilizers scenario depending on the initial soil carbon stocks.
[49] Finally, the potential sink of radiative forcing diminishes when fertilization increases and the difference between scenarios concerning the sink activity increases when increasing the initial soil content. Therefore it would be desirable to develop in future studies: (1) simulations with initialization procedures that account for the difference between the actual soil organic carbon stock and the longterm equilibrium values, and (2) transient runs from nonfertilized grasslands to fertilized ones (or the reverse), to assess the changes in the radiative forcing budget. Also, in order to make more realistic estimates of the greenhouse gas budget of grasslands at the continental scale, we urgently need to construct from diverse statistics available in various European countries a map of practices corresponding to the major types of management in each region.

[50] Acknowledgments. This work was funded by the EC under the contract EVK2-CT2001-00105 'GreenGrass'. N. V. gratefully acknowledges a grant from CEA.

\section{References}

Bouman, B. A. M., A. H. C. M. Schapendonk, W. Stol, and D. W. G. van Kraalingen (1996), Description of LINGRA, a model approach to evaluate potential productivities of grasslands in different European climate regions, in Quantitative Approaches in System Analysis 7, p. 58, DLO Res. Inst. for Agrobiol., Wageningen, Netherlands.

Bouwman, A. F. (1996), Direct emission of nitrous oxide from agricultural soils, Nutr. Cycling Agroecosyst, 46, 53-70.

CORINE (1995), CORINE Land cover Part 1: Methodology, EEA technical report, Comm. of the Eur. Communities, Brussels.

CORINE (2000), Addendum to the land cover technical guide, EEA technical report, Comm. of the Eur. Communities, Brussels.

Corrall, A. J. (1988), Prediction of production from grassland, in Information Bulletin of the FAO European Research Co-operative Network on Pastures and Field Crops, Herba 1, pp. 25-28, Agron. Inst. of the Univ. of Florence, Florence, Italy.

Food and Agriculture Organization (2002), Fertilizer use by crop, 67 pp., report, Rome.

Freibauer, A. (2003), Regionalised inventory of biogenic greenhouse gas emissions from European agriculture, Eur. J. Agron., 19(2), 135-160.

Freibauer, A., and M. Kaltschmitt (2003), Controls and models for estimating direct nitrous oxide emissions from temperate and sub-boreal agricultural mineral soils in Europe, Biogeochemistry, 63(1), 93-115.

Gibson, J. K., P. Kållberg, S. Uppala, A. Hernandez, A. Nomura, and E. Serrano (1997), ERA description, ERA-15 Proj. Rep. Ser. 1, Eur. Cent. for Medium-Range Weather Forecasts, Reading, UK

Global Soil Data Task Group (2000), Global gridded surfaces of selected soil characteristics (IGBP-DIS), http://www.daac.ornl.gov, Oak Ridge Natl. Lab. Distrib. Archive Cent., Oak Ridge, Tenn.

Intergovernmental Panel on Climate Change (1995), Climate Change 1994: Radiative Forcing of Climate Change and an Evaluation of the IPCC IS92 Emission Scenarios, 339 pp., Cambridge Univ. Press, New York.

Intergovernmental Panel on Climate Change (1997). Revised 1996 IPCC Guidelines for National Greenhouse Inventories, Paris.

Janssens, I. A., et al. (2003), Europe's terrestrial biosphere absorbs 7 to $12 \%$ of European anthropogenic $\mathrm{CO}_{2}$ emissions, Science, 300(5625), $1538-$ 1542 .

Marriott, C. A., M. Fothergill, B. Jeangros, M. Scotton, and F. Louault (2004), Long-term impacts of extensification of grassland management on biodiversity and productivity in upland areas: A review, Agronomie, 24, 447-462.

Mitchell, T. D., T. R. Carter, P. D. Jones, M. Hulme, and M. New (2004), A comprehensive set of high-resolution grids of monthly climate for Europe and the globe: The observed record $(1901-2000)$ and 16 scenarios (2001-2100), Work. Pap. 55, Tyndall Cent., Norwich, UK.

Mucher, C. A., K. T. Steinnocher, F. P. Kressler, and C. Heunks (2000), Land cover characterization and change detection for environmental monitoring of pan-Europe, Int. J. Remote Sens., 21, 1159-1181.

Myneni, R. B., et al. (2002), Global products of vegetation leaf area and fraction absorbed PAR from year one of MODIS data, Remote Sens. Environ., 83(1-2), 214-231.

Peylin, P., P. J. Rayner, P. Bousquet, C. Carouge, F. Hourdin, P. Heinrich, P. Ciais, and AEROCARB Contributors (2005), Daily $\mathrm{CO}_{2}$ flux estimates 
over Europe from continuous atmospheric measurements: 1. Inverse methodology, Atmos. Chem. Phys., 5, 3173-3186.

Pinarès-Patino, C. S., P. D’Hour, J.-P. Jouany, and C. Martin (2007), Effects of stocking rate on methane and carbon dioxide production by grazing cattle, Agric. Ecosyst. Environ., in press.

Riedo, M., A. Grub, M. Rosset, and J. Fuhrer (1998), A pasture simulation model for dry matter production, and fluxes of carbon, nitrogen, water and energy, Ecol. Modell., 105, 141-183.

Schmid, M., A. Neftel, M. Riedo, and J. Fuhrer (2001), Process-based modelling of nitrous oxide emissions from different nitrogen sources in mown grassland, Nutr. Cycl. Agroecosyst., 60, 177-187.

Scholefield, D., D. R. Lockyer, D. C. Whitehead, and K. C. Tyson (1991), A model to predict transformations and losses of nitrogen in UK pastures grazed by beef cattle, Plant Soil, 132, 165-177.

Soussana, J. F., P. Loiseau, N. Vuichard, E. Ceschia, J. Balesdent, T. Chevallier, and D. Arrouays (2004), Carbon cycling and sequestration opportunities in temperate grasslands, Soil Use Manage., 20 , $219-230$

Thornley, J. H. M. (1998), Grassland Dynamics: An Ecosystem Simulation Model, 241 pp., CABI Publ., Cambridge, Mass.

Vuichard, N. (2005), Modélisation des flux de gaz à effet de serre des prairies européennes, Ph.D. thesis, Univ. Pierre et Marie Curie, Paris.
Vuichard, N., P. Ciais, N. Viovy, C. Ammann, P. Calanca, J. Clifton-Brown, J. Fuhrer, M. B. Jones, C. Martin, and J. F. Soussana (2007), Estimating the greenhouse gas fluxes of European grasslands with a process-based model: 1. Model evaluation against in situ measurements, Global Biogeochem. Cycles, 21, GBXXXX, doi:10.1029/2006GB002611.

Webb, R. W., C. E. Rosenzweig, and E. R. Levine (2000), Global soil texture and derived water-holding capacities, http://www.daac.ornl.gov, Oak Ridge Natl. Lab. Distrib. Active Arch. Cent., Oak Ridge, Tenn.

P. Calanca, Agroscope Reckenholz-Tänikon, Research Station ART Air Pollution and Climate Group, Reckenholzstr. 191, CH-8046 Zurich, Switzerland.

P. Ciais and N. Viovy, Laboratoire des Sciences du Climat et de l'Environnement, CEA-CNRS, Bat 701, Orme des Merisiers, F-91191 Gifsur-Yvette, France.

J.-F. Soussana, INRA, UR874 Grassland Ecosystem Research, 234 Av. du Brézet, Clermont-Ferrand, F-63100, France.

N. Vuichard, Department of Forest Science and Environment, University Of Tuscia, Via de Lellis snc, I-01100 Viterbo, Italy. (vuichard@unitus.it) 